\title{
Purification Effect of Oysters Based on the Analysis of Environmental Parameters
}

\author{
Hanjiang Dong ${ }^{1}$, Dongsong Yan ${ }^{1}$, Liangyu Deng ${ }^{1}$, Hongfei Guo ${ }^{2,3}$, Keshan Wang ${ }^{4}$, Mengfan $\mathrm{Wu}^{1}$, Bingjie $\mathrm{Yu}^{2}$, \\ Jian Wang ${ }^{1}$, Haodong Fan $^{1}$ \\ ${ }^{1}$ School of Electrical Engineering, Jinan University, Zhuhai 519070, PR China \\ ${ }^{2}$ Institute of Physical Internet, Jinan University, Zhuhai 519070, PR China \\ ${ }^{3}$ School of Intelligent Systems Science and Engineering, Jinan University, Zhuhai 519070, PR China \\ ${ }^{4}$ Fuhua Casting and Forging Limited, Jiangmen 529147, PR China \\ Correspondence: Dongsong Yan, School of Electrical Engineering, Jinan University, Zhuhai 519070, PR China.
}

Received: May 30, 2019 Accepted: June 19, 2019 Online Published: June 21, 2019

doi:10.11114/set.v6i1.4299 URL: https://doi.org/10.11114/set.v6i1.4299

\begin{abstract}
With the development of coastal industries, marine pollution has intensified, and more and more shellfish in marine areas have been polluted to varying degrees. People's health can be compromised when eating contaminated shellfish. In the actual purification process of the shellfish purification plant project, there is no in-depth exploration of the parameters of the purification pond. Based on supplementing the basic research for the development of the oyster purification industry at different temperatures, salinities, $\mathrm{pH}$, ultraviolet lamp power, irradiation time, and water flow rate, we find the best environmental conditions are a temperature of $30^{\circ} \mathrm{C}$, a pH of 8 , a salinity of $32 \%$, an ultraviolet lamp illumination power of $9 \mathrm{w}$, an ultraviolet lamp irradiation time of $12 \mathrm{~h}$, and a water body flow rate of $0.5 \mathrm{~m} / \mathrm{s}$. We supplement basic research related to bioengineering in China. We hope that our results can provide reference for further research and contribute to the sustainable development of the oyster purification industry. Create economic benefits for society.
\end{abstract}

Keywords: oysters, purification technology, environmental parameters

\section{Introduction}

With the development of coastal industries, marine pollution has intensified. Contaminated areas include Italy's Campania region (Giovanna Fusco, 2017), Spain's Galicia rias region (David Polo, 2015), Xiamen, China (Youqing Cai, 2002, Zhinan Guo, 2014), China's Lianyungang Area (PengLi, 2019). Shellfish in these areas are contaminated to varying degrees, accumulating toxic substances, potentially pathogenic bacilli, and viruses. When people eat contaminated shellfish, their health is compromised. The transportation of aquatic products to the inland retail aquatic products market (Xiaoke Xu, 2016, Angelo DePaola, 2010) will further expand the spread of contaminated shellfish. Exposure to toxic substances such as inorganic arsenic, methylmercury (PengLi, 2019), and lead (Ye He, 2016) increases the risk of cancer. Potential pathogenic bacilli and viruses can cause outbreaks of fulminant gastroenteritis. Norovirus (NVs) (Changsun Choi, 2016, Keleigh Provost, 2011) has become a major cause of viral gastroenteritis. Vibrio parahaemolyticus (Anna Mottola, 2016) has increased the incidence of gastroenteritis.

Many scholars have done research on shellfish, taking oysters as an example. Cerco (Cerco Carl F., 2015) describes a series of linking modules for calculating benefits, including Crassostrea bioenergetics, material transport through tidal prisms, and quantification of benefits. Rasmussen (Rasmussen Lasse Dam, 2016) demonstrated at a molecular level that oysters can act as a carrier for Norovirus GII.P17-GII. Mattarozzi (Mattarozzi Monica, 2016) proposed a desorption electrospray ionization-high resolution mass spectrometry (DESI-HRMS) for screening for the presence of paralytic shellfish toxins in sputum. Schaeffer (Schaeffer Julien, 2018) found that increasing the efficiency of wastewater treatment can reduce norovirus contamination in oysters.

In fact, shellfish purification plant engineering has been promoted worldwide (Qinglin Qiao, 2000), including the United States, Australia, New Zealand, the Philippines, Thailand, Malaysia, the United Kingdom, Italy, Canada, Spain, 
France and so on. The United Kingdom was the first country to begin research and application of shellfish purification technology, and its purification was mainly in the ultraviolet system (Hua Yang, 2004). In China, the shellfish purification industry started late. In the 2015 support plan, the Ministry of Science and Technology of China explicitly included the research and development of aquaculture economical shellfish purification technology (Qing Lin, 2018). Actually, in China, the parameters in the purification pool are set according to the shellfish growth environment, and there is no in-depth exploration of the setting of each parameter.

We tried to explore the effects of temperature, salinity, $\mathrm{pH}(\mathrm{pH})$, ultraviolet (UV) lamp power, irradiation time, purified water flow rate and other variables on the purification effect of oysters, so as to find the optimal parameters for oyster purification. We want to fill the gap in China's theoretical research on this aspect and supplement relevant basic research for the oyster purification industry.

\section{Method}

\subsection{Experimental Materials}

Oysters used in the experiment are called Fujian oyster, which are taken from the Hengqin Oyster Breeding Base in Zhuhai City, Guangdong Province. After selecting individual oyster samples with similar size, good appearance and well health, we removed the shell attachments, washed them with sea water, and weighed the live weight with an electronic balance to make an average of $75.0 \pm 1.6 \mathrm{~g}$. Each set of experimental samples was processed within three to four hours of sampling. The oysters were temporarily fed with chlorella in the experiment.

\subsection{Experimental Method}

Our work includes designing experimental devices, conducting experiments, acquiring data, and analyzing data in four major parts.

\subsubsection{Design of Experimental Device}

The design of the experimental device includes designing the purification device in the preliminary filtration stage of seawater, the device used to adjust various parameters in the pretreatment of seawater during the experiment, and the device used in the purification process.

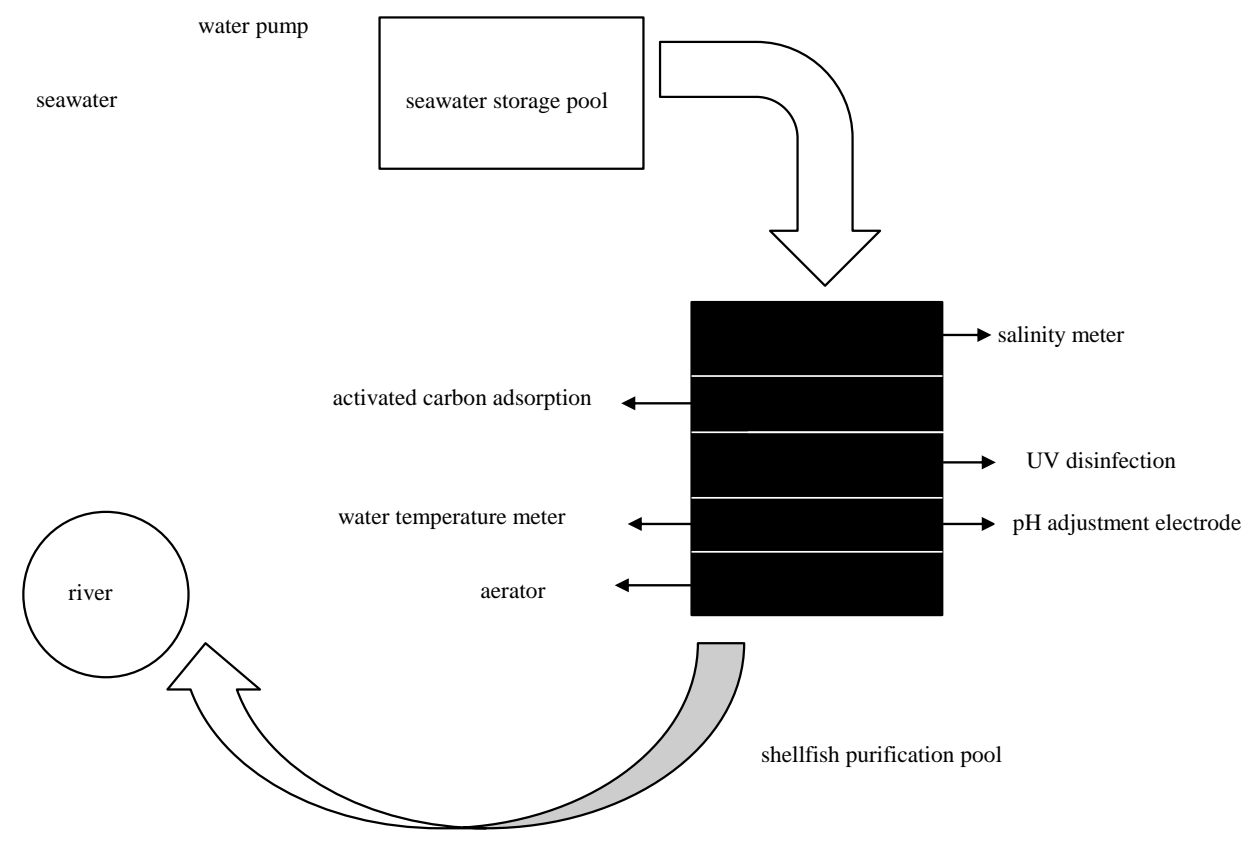

Figure 1. Figure title (This is an example of figure 1)

During the experiment, device is as shown above. As we can see, injecting seawater from the outside consists of three different parts: preliminary filtration, pretreatment, and shellfish temporary purification. Preliminary filtration removes a large amount of garbage and sediment in the seawater. Experimental pretreatment adjusts various parameters. Shellfish temporary purification is the simulated reduction of the actual shellfish purification process.

During the experiment, we control variables and conduct interactive experiments. Each time we change one or two of the variables, then perform multiple sets of controlled trial. Through the analysis of a large number of experimental datas, the law is finally explored. 
In terms of data acquisition, in order to analyze the purification effect of oysters, the water filtration rate after sputum purification is measured, which is an important reference index for the physiological state after sputum purification.

Playing an important role in the feeding behavior and energy science of shellfish, filtration rate is an important parameter in evaluating the purification effect and is widely used as the total volume of filtered water in the filter-feeding shellfish per unit time, which is an important indicator that reflects the physiological state of shellfish.

Shellfish, seawater and bait are placed in a water tank and samples are taken at intervals in order to measure the concentration of bait in the water. The clear filter (CR) is calculated according to the following formula. When the retention rate of shellfish to bait pellets reaches $100 \%$, the filtration rate is equal to the clearance rate.

$$
C R=\left(\frac{V}{\mathrm{nt}}\right) \times \operatorname{Ln}\left(\frac{C_{0}}{\mathrm{C}_{t}}\right)
$$

Where:

$C_{0}=$ the concentration of the bait in the box at the beginning of the experiment;

$\mathrm{C}_{t}=$ the concentration of the bait when the concentration of the bait in the tank reaches equilibrium after a period of $\mathrm{t}$.

The values of $C_{0}$ and $\mathrm{C}_{t}$ are determined by hemocyte plate counting method. The method is simple in operation, requires less capital, and the obtained data is accurate.

\subsubsection{Explore Impact of Salinity on Purification of Oysters}

Method of regulating seawater salinity: The salinity of natural seawater is 31 . Low-salinity seawater is prepared by adding fully aerated tap water to natural seawater. High-salinity seawater is prepared by adding sea salt and performing adequate aeration. The salinity is measured by a salinity meter.

Experimental specific steps: Experiments were carried out in a static water system with six groups of salinity gradients of $24,26,28,30,32$, and 34 . The temperature of the system was maintained at $25^{\circ} \mathrm{C}$ through a thermostat. After the start of the test, we placed 3 Oyster individuals in each salinity gradient group. The water didn't be changed during the experiment. After 24 hours, we collected the data and calculated the water filtration rate of each group of oysters by the formula. We repeated the experiment several times and took the average.

\subsubsection{Explore Impact of Temperature on Purification of Oysters}

Method of regulating temperature: Heating by thermostat is used to adjust the seawater to the experimental conditions.

Experimental specific steps: Five sets of temperature gradients of $15{ }^{\circ} \mathrm{C}, 20^{\circ} \mathrm{C}, 25^{\circ} \mathrm{C}, 30{ }^{\circ} \mathrm{C}$, and $35^{\circ} \mathrm{C}$ were set in the static water system. The salinity of the system was adjusted at about 32 . After the start of the test, we placed 3 Oyster individuals in each temperature gradient group. Water didn't be changed during the experiment. After 24 hours, we collected the data and calculated the water filtration rate of each group of oysters by the formula. We repeated the experiment several times and took the average.

\subsubsection{Explore Impact of power Hydrogen $(\mathrm{pH})$ on Purification of Oysters}

Method of regulating $\mathrm{pH}$ : The $\mathrm{pH}$ adjustment is divided into coarse adjustment and fine adjustment. The coarse adjustment uses the method of adding $\mathrm{HCl}$ solution (reduce $\mathrm{pH}$ ) and adding $\mathrm{NaOH}$ solution (increase $\mathrm{pH}$ ); The fine adjustment uses the method of passing high-purity $\mathrm{CO} 2$ (reduce $\mathrm{pH}$ ) and adding quick lime (increase $\mathrm{pH}$ ).

Experimental specific steps: Experiments were carried out in a static water system with five groups of $\mathrm{pH}$ gradients of 5, $7,8,9$, and 10 . The salinity of the system is adjusted at about 32. After the start of the test, we placed 3 Oyster individuals in each $\mathrm{pH}$ gradient group. The water didn't be changed during the experiment. After 24 hours, we collected the data and calculated the water filtration rate of each group of oysters by the formula. We repeated the experiment several times and took the average.

\subsubsection{Explore Impact of Power and Exposure Time of Ultraviolet (UV) Lamp on Purification of Oysters}

In this experiment, the power of the UV lamp and the duration of the irradiation were used as independent variables. We adjusted the power of the light and the duration of the illumination by changing the type of the UV lamp and the time of energization.

The different light power gradients and the illumination duration gradients were set separately, and the water filtration rate of the oysters was measured under different gradient conditions.

1) UV Lamp Power Gradients Experiment 
In the static water system with the UV lamp irradiation condition, we set five UV lamp power gradients groups of $0,5 \mathrm{w}$, $7 \mathrm{w}, 9 \mathrm{w}$, and $11 \mathrm{w}$. The temperature of the system was adjusted at $30^{\circ} \mathrm{C}$. The $\mathrm{pH}$ was adjusted to about 8 . The salinity was adjusted to about 32. After the start of the test, we placed 3 Oyster individuals in each UV lamp power gradient group. The water didn't be changed during the experiment. After irradiating the static water system with UV lamp for 6 hours and waiting for 24 hours, we collected data. Based on the data, we calculated the water filtration rate of each group of oysters by the formula. We repeated the experiment several times and took the average.

\section{2) UV Lamp Irradiation Time Gradients Experiment}

In the static water system with the UV lamp irradiation condition, we set four illumination duration gradients groups of $0 \mathrm{~h}, 6 \mathrm{~h}, 12 \mathrm{~h}$, and $24 \mathrm{~h}$. The temperature of the system was adjusted at $30^{\circ} \mathrm{C}$. The $\mathrm{pH}$ was adjusted to about 8 . The salinity was adjusted to about 32. After the start of the test, we placed 3 Oyster individuals in each UV lamp power gradient group. The water didn't be changed during the experiment. After irradiating the static water system with UV lamp for different illumination duration gradients, we collected data. Based on the data, we calculated the water filtration rate of each group of oysters by the formula. We repeated the experiment several times and took the average.

\subsubsection{Explore Impact of Flow Velocity on Purification of Oysters}

Method of regulating flow velocity: The flow velocity is controlled by adjusting the power of the pump and changing the diameter of the water conduit. Before the test, we should establish a one-to-one mapping of the pump's power to the water's flow velocity.

There are a great number of methods to calculation the filtration rate. Since the purification system is a dynamic system, the clear filtration method is not easy to operate and the error is large. We use a running water tank method to measuring the filtration rate of the experimental group.

Experimental specific steps: Flow conditions through an external water pump was added in the purification system. We set five sets of flow gradients of $0 \mathrm{t} / \mathrm{h}, 0.5 \mathrm{t} / \mathrm{h}, 1 \mathrm{t} / \mathrm{h}, 1.5 \mathrm{t} / \mathrm{h}, 2 \mathrm{t} / \mathrm{h}$. The temperature of the group was adjusted at $30{ }^{\circ} \mathrm{C}$, the $\mathrm{pH}$ was adjusted at about 8 , and the salinity was adjusted at about 32 . Three individuals were placed in each experimental group. After 24 hours, the data were measured, and the water filtration rate of each group was calculated by the formula. We repeated the experiment several times and took the average.

\section{Results}

\subsection{Impact of Salinity on Purification of Oysters}

The oyster filtration rate of experiment group in different temperature is shown in Table 1 below.

Table 1. Oyster Filtration Rate of Experiment Group in Different Temperature

\begin{tabular}{lccccc}
\hline Temperature $/{ }^{\circ} \mathrm{C}$ & 15 & 20 & 25 & 30 & 35 \\
\hline Filtration Rate/L/(per*h) & 0.096 & 0.331 & 0.310 & 0.396 & 0.047 \\
\hline
\end{tabular}

Drawing the data as a line chart, which is as shown in Figure 1 below.

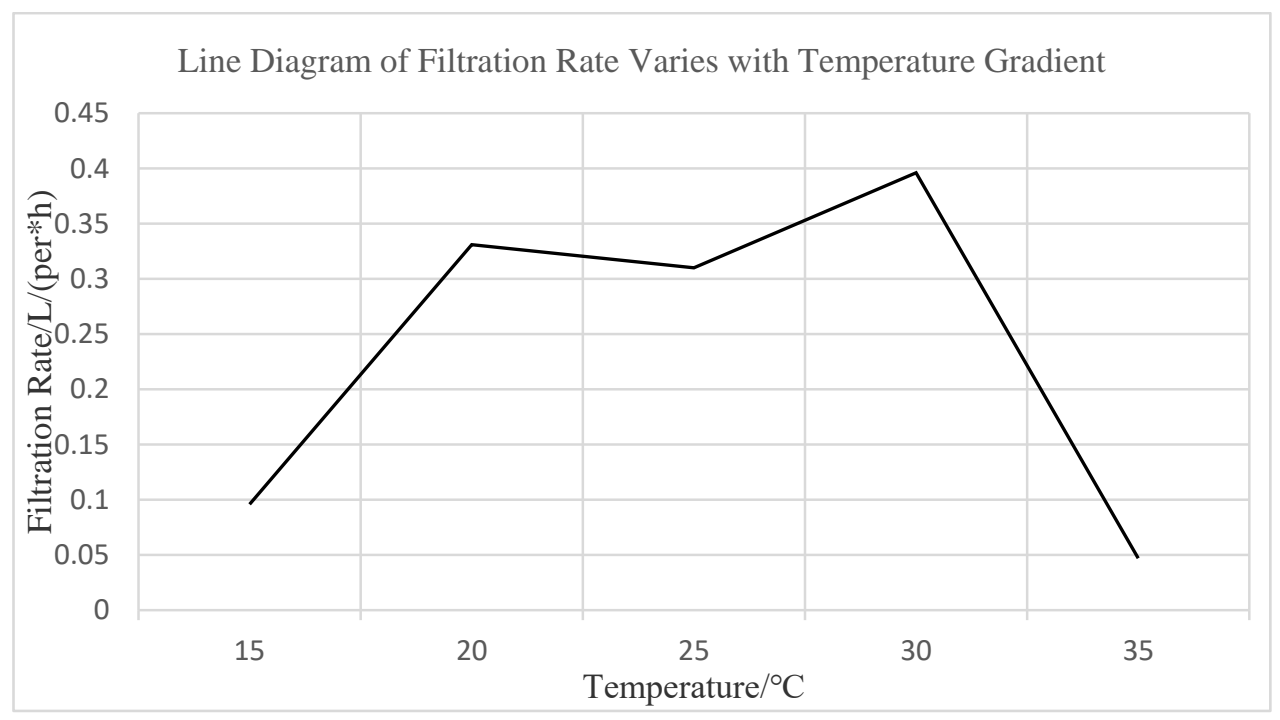

Figure 1. Line Diagram of Filtration Rate Varies with Temperature Gradient

We studied the effect of salinity change on the filtration rate of shellfish. In order to study the influence of salinity 
single factor, we used a hydrostatic system, which effectively eliminates the interference of flow rate, power $\mathrm{pH}$, temperature and other factors. The results show that when salinity is between 26 and 34, with the increase of salinity, the filtration rate of oysters increases first and then decreases. The filtration rate of oyster peaks at a salinity of 32 , but the change of the filtration rate remains relatively stable at a salinity between 24 and 34 .

Salinity has an extremely important influence on the physiological activities such as feeding, breathing and excretion of oysters, which is related to the ability of osmotic pressure regulation of oysters (Huayang Guo, 2012). When the salt is low, the osmotic pressure changes to cause the oysters to close the inlet and outlet pipes or shells to protect the body from low salt. When the salinity is suitable, the oysters are regulated by osmotic pressure to maintain the stability of the body environment to keep the activity of various enzymes in the body. When the environmental salinity exceeds their tolerance range, oysters cannot maintain the stability of the body environment by regulating the osmotic pressure, eventually leading to death. When the low salt causes the oysters to close the inlet, outlet or shell, the exchange capacity of the oysters and the outside water is reduced, causing the feeding activity to stop, and the filtration rate is correspondingly reduced, thereby reducing the purification effect of the oysters; in the suitable range of salinity, the filtration rate increases with the increase of salinity. After reaching the maximum value, the filtration rate decreases with the increase of salinity. At this time, the exchange channel between the oysters and the outside is weakened or even closed, which also causes the purification effect of oysters to decrease, which is a physiological protective response produced by oysters for a long time to adapt to the natural living environment.

After the regression analysis, the relationship between the salinity $(\chi)$ and the filtration rate $(y)$ can be fitted as follows:

$$
\begin{gathered}
y=-0.0041 x^{2}+0.0618 x-0.0181 \\
\left(r^{2}=0.9893\right)
\end{gathered}
$$

which is possible to find the filtration rate corresponding to different salinities within the salinity range between 22 and 34 .

\subsection{Impact of Temperature on Purification of Oysters}

The oyster filtration rate of experiment group in different salinity is shown in Table 2 below.

Table 2. Oyster Filtration Rate of Experiment Group in Different Salinity

\begin{tabular}{lccccc}
\hline Salinity/\% & 24 & 26 & 28 & 30 & 32 \\
\hline Filtration Rate/L/(per*h) & 0.216 & 0.224 & 0.248 & 0.254 & 0.266
\end{tabular}

Drawing the data as a line chart, which is as shown in Figure 2 below.

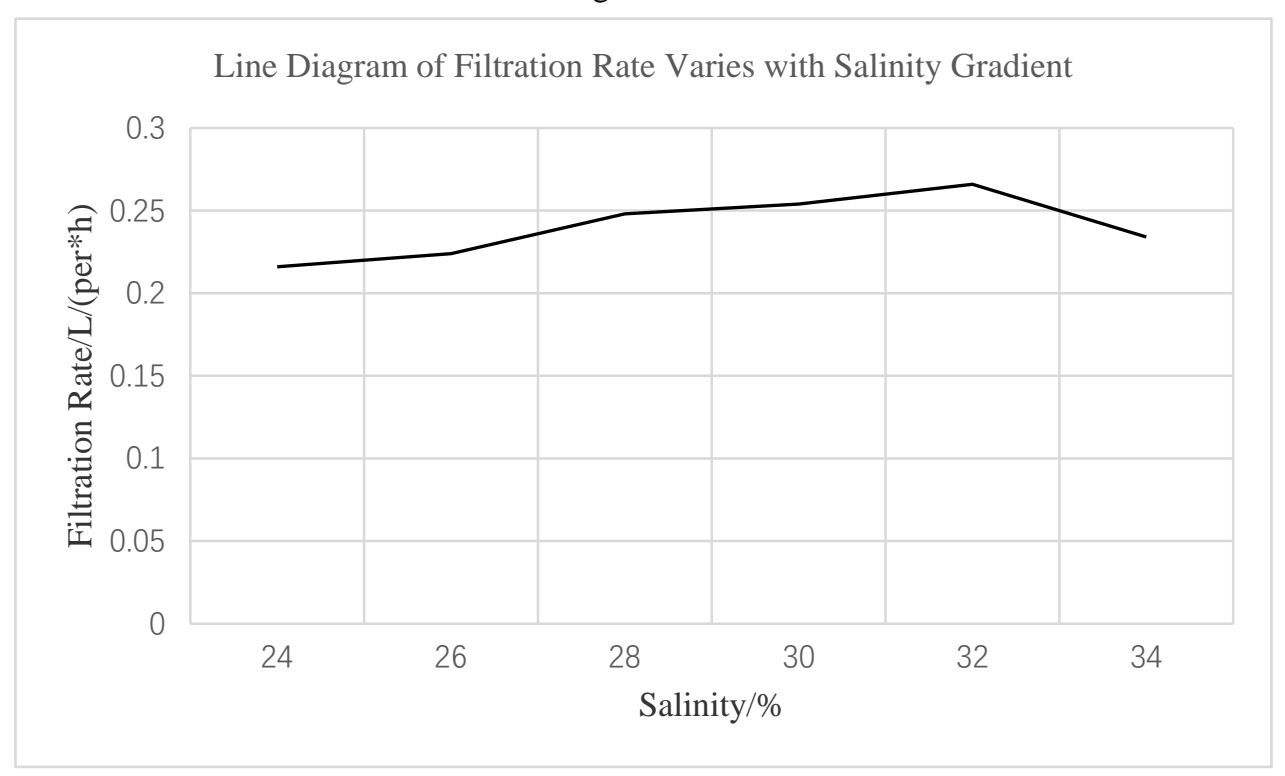

Figure 2. Line Diagram of Filtration Rate Varies with Salinity Gradient

The results show that temperature is also an important environmental factor which affects the filtration rate of oysters. The filtration rate of oysters has a suitable temperature range, that is, the optimal temperature range of shellfish, and the maximum filtration rate also appears at a certain temperature in this interval. In the range of 20 to $30{ }^{\circ} \mathrm{C}$, as shown in the results, the filtration rate of oysters is much higher than other temperature gradients, and the optimum temperature of oysters in the experimental group is about $30^{\circ} \mathrm{C}$. 
The reason for this may be as follows (Youqing Xu, 2012). When oysters live outside the suitable temperature range, they need to consume more energy to adapt to the environment, which reduces the vitality of the feeding organs and the filtration rate. In turn, the purification effect of the oysters is reduced. Besides, when the shellfish is outside the suitable temperature, the living state will change greatly. For example, the heart rate is slowed down and the strength is reduced, resulting the decreases in frequency of gill cilia oscillation, filtration rate, exchange between external environment, and purification effect.

\subsection{Impact of $\mathrm{pH}$ on Purification of Oysters}

The oyster filtration rate of experiment group in different $\mathrm{pH}$ is shown in Table 3 below.

Table 3. Oyster Filtration Rate of Experiment Group in Different $\mathrm{pH}$

\begin{tabular}{lccccc}
\hline $\mathrm{pH}$ & 6 & 7 & 8 & 9 & 10 \\
\hline Filtration Rate/L/(per*h) & 0.351 & 0.336 & 0.362 & 0.284 & 0.243 \\
\hline
\end{tabular}

Drawing the data as a line chart, which is as shown in Figure 3 below.

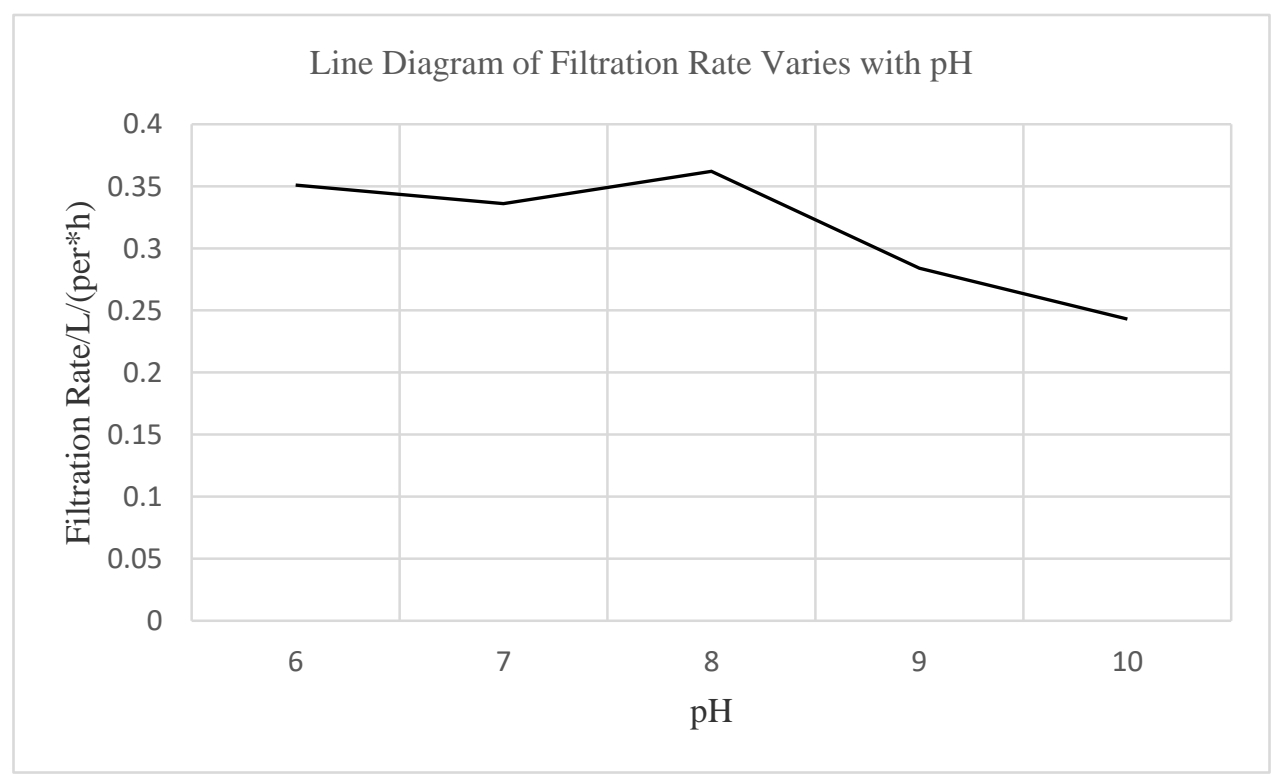

Figure 3. Line Diagram of Filtration Rate Varies with $\mathrm{pH}$

The results show that $\mathrm{pH}$ is also an important environmental factor affecting the water filtration rate of oysters. The change law is shown in Figure 3. In the range of $\mathrm{pH}$ 6.0 10.0, the water filtration rate of oysters appears like a wave. When the $\mathrm{pH}$ is 6 and 8 , the water filtration rate of oysters gradually increases, but the change is not significant. When the $\mathrm{pH}$ is higher than 8 , the water filtration rate of oysters decreases significantly with the increase of $\mathrm{pH}$. In this experiment, the filtration rate reaches the maximum when $\mathrm{pH}$ is 8.0.

Related studies have shown (Zhihua Liu, 2012) that low pH has an obvious negative effect on the physiological metabolism of oysters. Edible oysters, long oysters and mussels are in a near paralyzed state if $\mathrm{pH}$ is lower than 6 , extremely inactive, eventually leading to a decline in shell growth rate, weight gain rate, and an increase in mortality. High $\mathrm{pH}$ also has an adverse effect on the physiological metabolism of oysters. Some shellfish have a mortality rate of $20 \%$ and $40 \%$ at pH 9 and 10, respectively, which seriously affects the purification effect of oysters.

\subsection{Impact of Power and Exposure Time of Ultraviolet (UV) Lamp on Purification of Oysters}

The oyster filtration rate of experiment group in different UV lamp irradiation power gradient is shown in Table 4 below.

Table 4. Oyster Filtration Rate of Experiment Group in Different UV Lamp Irradiation Power Gradient

\begin{tabular}{lccccc}
\hline Power/W & 0 & 5 & 7 & 9 & 11 \\
\hline Filtration Rate/L/(per*h) & 0.354 & 0.403 & 0.467 & 0.483 & 0.472 \\
\hline
\end{tabular}

Drawing the data as a line chart, which is as shown in Figure 4 below. 


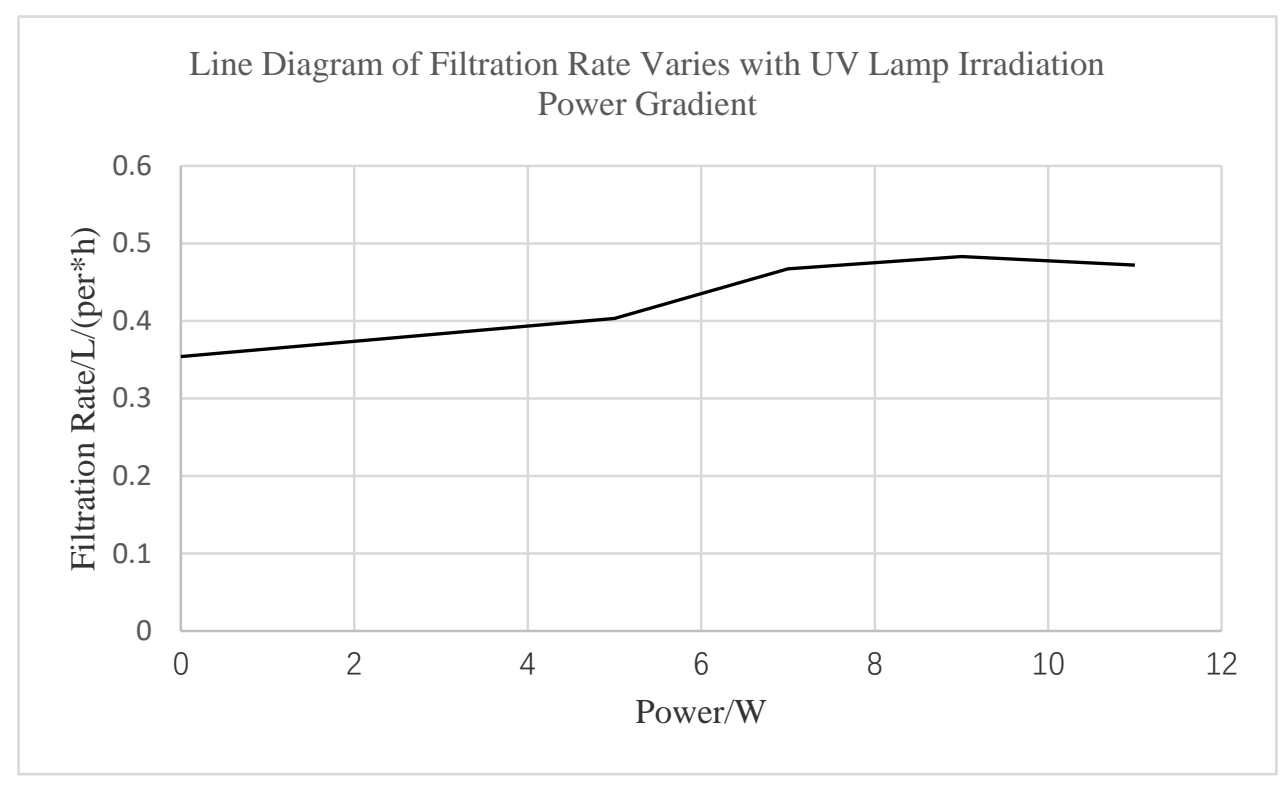

Figure 4. Line Diagram of Filtration Rate Varies with UV Lamp Irradiation Power Gradient

The results show that the UV lamp irradiation has a significant effect on the purification of oysters, and within a certain range, the filtration rate of oysters increases with the increase of the irradiation power, and tends to be stable after increasing to a certain value. In the experiment, the water filtration rate of the oysters reached a maximum at an irradiation power of $9 \mathrm{~W}$, and then stabilized.

After the UV lamp irradiation, there is a significant increase in the water filtration rate of the oysters. This may be due to the presence of a large number of parasitic strains in the oysters during the growth process, such as Escherichia coli, Sstreptococcus and so on. After being killed by UV lamp, the activity of oyster is increased, thereby improving the purification effect of the shellfish. After 6 hours of UV light irradiation with different powers, there is a tendency for the germination rate to rise. Among them, there may be problems in whether UV lamps of different powers will kill most of the bacteria in the oyster body (Qinglin Qiao, 2004). With the increase of the power of the UV lamp, the ultraviolet penetrating power is enhanced and the sterilization effect is also superior. Finally, the oyster filtration rate tends to be stable because the bacteria in the oyster body have been mostly killed, and the increase in power can not improve the purification effect of oysters.

The oyster filtration rate of experiment group in different UV lamp irradiation time is shown in Table 5 below.

Table 5. Oyster Filtration Rate of Experiment Group in Different UV Lamp Irradiation Time

\begin{tabular}{lcccc}
\hline Time/s & 0 & 6 & 12 & 24 \\
\hline Filtration Rate/L/(per*h) & 0.360 & 0.501 & 0.514 & 0.509
\end{tabular}

Drawing the data as a line chart, which is as shown in Figure 5 below. 


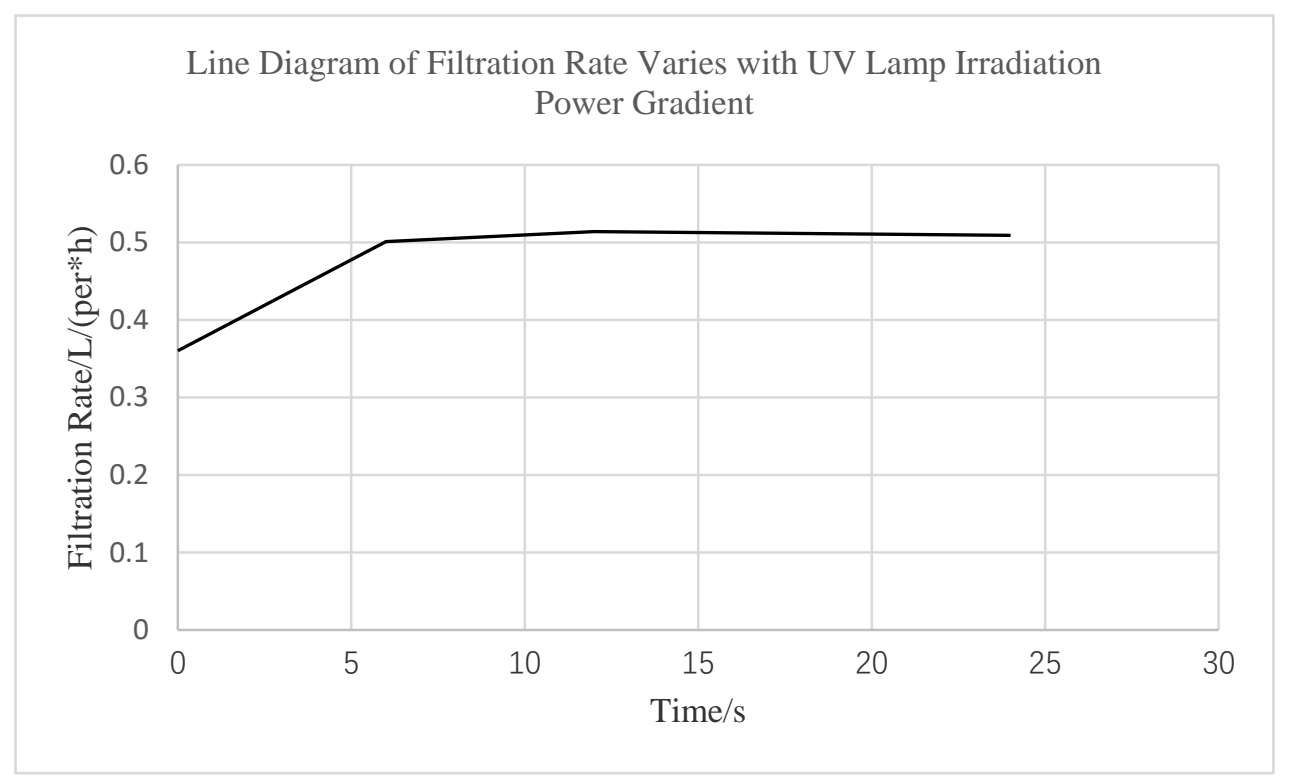

Figure 5. Line Diagram of Filtration Rate Varies with UV Lamp Irradiation Time

The results show that the UV lamp irradiation has a significant effect on the purification of oysters, and the regularity is consistent with different irradiation powers. Within a certain range, the filtration rate of oysters increases with the increase of irradiation time, and increases to a certain value. It tends to be stable. In the experiment, the water filtration rate of the oysters reached a maximum at an irradiation time of $12 \mathrm{~h}$, and then stabilized. After the UV lamp of the same power is irradiated for different time, the trend of the germination rate increases, which may be consistent with the different power irradiation for $6 \mathrm{~h}$.

There may also be the problem of whether the UV lamp irradiation at different times wil kill most of the bacteria in the oyster body. As the UV lamp irradiation time increases, the ultraviolet sterilization effect is more complete. Finally, the sputum filtration rate tends to be stable because the bacteria in the oyster body have been mostly killed, and the increase of the irradiation time cannot improve the purification effect of oysters.

3.5 Impact of Flow Velocity on Purification of Oysters

The oyster filtration rate of experiment group in different flow velocities is shown in Table 6 below.

Table 6. Oyster Filtration Rate of Experiment Group in Different Flow Velocities

\begin{tabular}{lcccc}
\hline Flow Velocity/m/s & 0 & 8 & 12 & 24 \\
\hline Filtration Rate/L/(per*h) & 0.360 & 0.501 & 0.514 & 0.509 \\
\hline
\end{tabular}

Drawing the data as a line chart, which is as shown in Figure 6 below. 


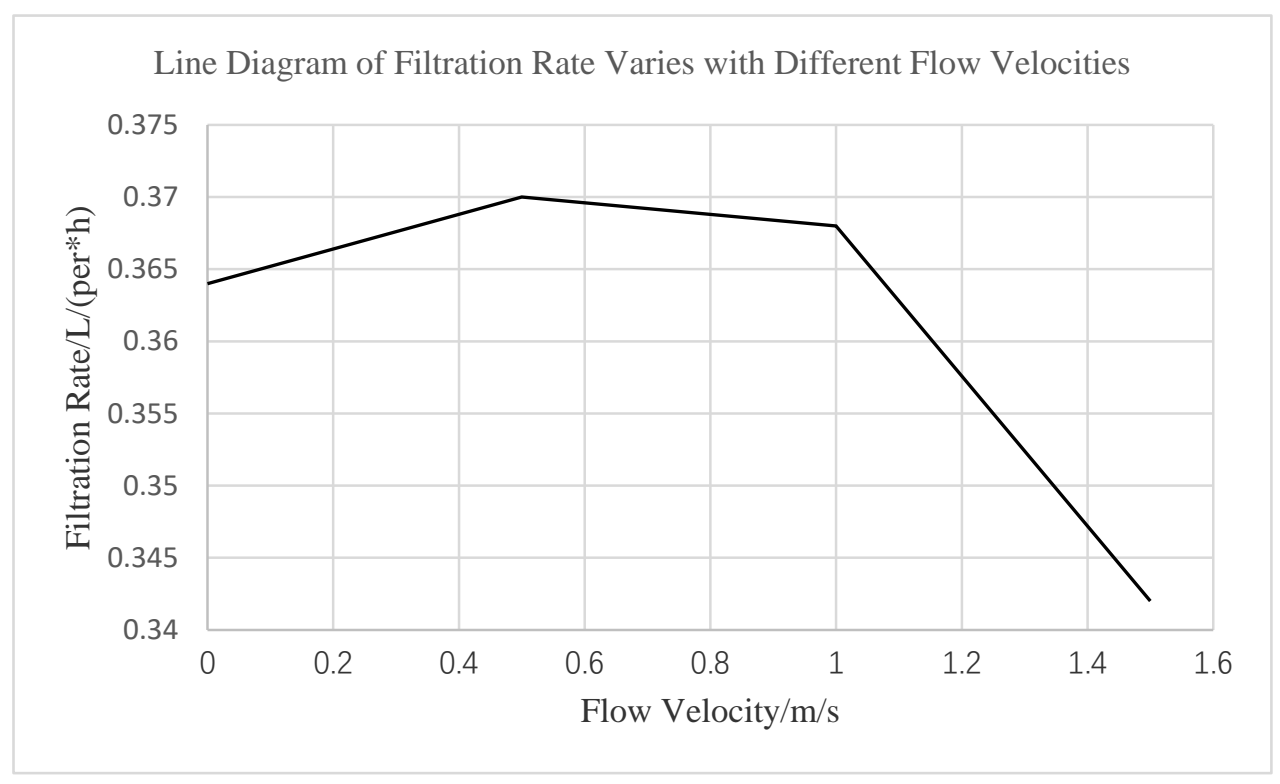

Figure 6. Line Diagram of Filtration Rate Varies with Different Flow Velocities

The results show that the flow rate has no significant effect on the water filtration rate of oysters, but the filtration rate of oysters has a certain regularity with the change of flow rate. The filtration rate of oysters increases first and then decreases with the increase of flow rate. The segment changes more significantly. In the experiment, the oysters achieved the best purification effect at a flow rate of $0.5 \mathrm{t} / \mathrm{h}$.

This situation may be related to the exchange of oysters and aquaculture water. Due to the continuous pollution of the nearby water bodies during the oyster filter purification process, when the oysters are in a still water state, the nearby water bodies are quickly fouled. There is a saturation value for the effect. When the oysters are in a state of flowing water, since the water body is constantly being renewed, some of the sputum and microorganisms are easily entangled by the water body, so the water filtration rate of the oysters is increased. However, as the water flow rate increases, the filter-feeding effect of oysters is hindered, and oysters are in a state of stress protection, which will weaken or even close the exchange channels with the outside world, thereby reducing the purification effect of oysters.

\section{Discussion}

We are based on the basic research for the development of the oyster purification industry, so the entry point is very fine. We explored the best parameters for purifying oysters in the project purification system among various variables such as temperature, salinity, $\mathrm{pH}$, UV lamp power, irradiation time, and water flow rate.

The best environmental conditions are a temperature of $30^{\circ} \mathrm{C}$, a $\mathrm{pH}$ of 8 , a salinity of $32 \%$, an UV lamp illumination power of $9 \mathrm{w}$, an UV lamp irradiation time of $12 \mathrm{~h}$, and a water body flow rate of $0.5 \mathrm{~m} / \mathrm{s}$. We supplement basic research related to bioengineering in China.

Through the above experimental analysis and summary, we believe that there are still many gray areas in the field of oyster purification that require scientific research, such as the stress mechanism of oysters in different environments. With the new generation of industrial transformation and consumption upgrading, the oyster purification industry will create more economic benefits. We hope that our results can provide reference for further research and contribute to the sustainable development of the oyster purification industry.Then indirectly create economic benefits for society.

\section{References}

American Psychological Association. (1972). Ethical standards of psychologists. Washington, DC: American Psychological Association.

Anderson, C. A., Gentile, D. A., \& Buckley, K. E. (2007). Violent video game effects on children and adolescents: Theory, research and public policy. https://doi.org/10.1093/acprof:oso/9780195309836.001.0001

Beck, C. A. J., \& Sales, B. D. (2001). Family mediation: Facts, myths, and future prospects. Washington, DC: American Psychological Association. https://doi.org/10.1037/10401-000

Bernstein, T. M. (1965). The careful writer: A modern guide to English usage (2nd ed.). New York, NY: Atheneum.

Bjork, R. A. (1989). Retrieval inhibition as an adaptive mechanism in human memory. In H. L. Roediger III, \& F. I. M. 
Craik (Eds.), Varieties of memory \& consciousness (pp. 309-330). Hillsdale, NJ: Erlbaum.

Cress, C. M. (2009). Curricular strategies for student success and engaged learning [PowerPoint slides]. Retrieved from http://www.vtcampuscompact.org/2009/TCL_post/presenter_powerpoints/Christine\%20Cress\%20-\%20Curricular \%20Strategies.ppt

Driedger, S. D. (1998, April 20). After divorce. Maclean's, 111(16), 38-43.

Gibbs, J. T., \& Huang, L. N. (Eds.). (1991). Children of color: Psychological interventions with minority youth. San Francisco, CA: Jossey-Bass.

Gilbert, D. G., McClernon, J. F., Rabinovich, N. E., Sugai, C., Plath, L. C., Asgaard, G., ... Botros, N. (2004). Effects of quitting smoking on EEG activation and attention last for more than 31 days and are more severe with stress, dependence, DRD2 A 1 allele, and depressive traits. Nicotine and Tobacco Research, 6, 249-267. https://doi.org/10.1 080/1462220041 0001676305

Goleman, D. (2009). What makes a leader? In D. Demers (Ed.), AHSC 230: Interpersonal communication and relationships (pp. 47-56). Montreal, Canada: Concordia University Bookstore. (Reprinted from Harvard Business Review, 76(6), pp.93-102, 1998).

Guignon, C. B. (1998). Existentialism. In E. Craig (Ed.), Routledge encyclopedia of philosophy (Vol. 3, pp. 493-502). London, England: Routledge.

Klimoski, R., \& Palmer, S. (1993). The ADA and the hiring process in organizations. Consulting Psychology Journal: Practice and Research, 45(2), 10-36. https://doi.org/10.1037/1061-4087.45.2.10

Kubrick, S. (Director). (1980). The Shining [Motion picture]. United States: Warner Brothers.

MacIntyre, L. (Reporter). (2002, January 23). Scandal of the Century [Television series episode]. In H. Cashore (Producer), The fifth estate. Toronto, Canada: Canadian Broadcasting Corporation.

McLuhan, M. (1970a). Culture is our business. New York, NY: McGraw-Hill.

McLuhan, M. (1970b). From cliche to archetype. New York, NY: Viking Press.

Mellers, B. A. (2000). Choice and the relative pleasure of consequences. Psychological Bulletin, 126, 910-924. https://doi.org/10.1037/0033-2909.126.6.910

Postman, N. (1979). Teaching as a conserving activity. New York, NY: Delacorte Press.

Postman, N. (1985). Amusing ourselves to death: Public discourse in the age of show business. New York, NY: Viking.

Semenak, S. (1995, December 28). Feeling right at home: Government residence eschews traditional rules. Montreal Gazette, p. A4.

\section{Copyrights}

Copyright for this article is retained by the author(s), with first publication rights granted to the journal.

This is an open-access article distributed under the terms and conditions of the Creative Commons Attribution license which permits unrestricted use, distribution, and reproduction in any medium, provided the original work is properly cited. 